\title{
DNA methylation: an epigenetic mark of cellular memory
}

\author{
Mirang $\mathrm{Kim}^{1,2}$ and Joseph Costello ${ }^{3}$ \\ DNA methylation is a stable epigenetic mark that can be inherited through multiple cell divisions. During development and \\ cell differentiation, DNA methylation is dynamic, but some DNA methylation patterns may be retained as a form of epigenetic \\ memory. DNA methylation profiles can be useful for the lineage classification and quality control of stem cells such as \\ embryonic stem cells, induced pluripotent cells and mesenchymal stem cells. During cancer initiation and progression, genome- \\ wide and gene-specific DNA methylation changes occur as a consequence of mutated or deregulated chromatin regulators. Early \\ aberrant DNA methylation states occurring during transformation appear to be retained during tumor evolution. Similarly, DNA \\ methylation differences among different regions of a tumor reflect the history of cancer cells and their response to the tumor \\ microenvironment. Therefore, DNA methylation can be a useful molecular marker for cancer diagnosis and drug treatment. \\ Experimental \& Molecular Medicine (2017) 49, e322; doi:10.1038/emm.2017.10; published online 28 April 2017
}

\section{INTRODUCTION}

The identities of cells and tissues in multicellular organisms can be maintained by their particular epigenome. ${ }^{1}$ DNA methylation is a relatively stable component of the epigenome, which establishes and stabilizes cellular phenotypes by maintaining gene expression states. ${ }^{2-4}$ DNA methylation patterns for a particular cell type are inherited through successive cell cycles and extended through a specific lineage. ${ }^{5,6}$ DNA methylation can reflect the tissue of origin even after long-term culture. ${ }^{7,8}$ Furthermore, induced pluripotent stem cells (iPSCs), reprogrammed from mature cells by defined transcription factors, are found to harbor residual DNA methylation from the original donor cells. ${ }^{9,10}$

The term 'epigenetics' was coined by Waddington ${ }^{11}$ in 1942 to refer to 'the causal mechanisms by which the genes of a genotype bring about a phenotype'. Currently, the widely accepted definition of 'epigenetics' is 'heritable changes in genome function that occur without changes in the DNA sequence'. ${ }^{12}$ This definition implies that particular states that define cell identity are heritable and maintained. ${ }^{13}$ Here we discuss epigenetic memory, a natural mechanism by which the identity of a cell is maintained through successive cell cycles during development and differentiation. ${ }^{5,14}$

This review covers DNA methylation as a form of epigenetic memory in stem cells and cancer cells. We have organized this review into three main sections. The first section is an introduction to DNA methylation in mammals. We briefly describe the mechanisms of maintenance and erasure of DNA methylation and de novo DNA methylation. We also introduce DNA methylation analysis technologies. The second section summarizes DNA methylation as a mechanism of epigenetic memory in various types of stem cells, including embryonic stem cells (ESCs), iPSCs, hematopoietic stem cells (HSCs), mesenchymal stem cells (MSCs) and neural stem cells (NSCs). The last section is devoted to the role of DNA methylation in cancer initiation and evolution. We also describe DNA methylation as a marker of cancer origin and discuss its use in classifying cancer of unknown primary.

\section{DNA METHYLATION}

DNA methylation on the fifth position of cytosine $(5 \mathrm{mC})$ is a stable epigenetic mark that has important roles in mammalian development, differentiation and maintenance of cellular identity through the control of gene expression. ${ }^{15}$ Over the past 40 years, changes in DNA methylation have been observed in many human diseases, especially cancer. ${ }^{16}$

DNA methylation in vertebrates is mainly restricted to $\mathrm{CpG}$ sites, but significant non-CpG methylation has been found in pluripotent stem cells. ${ }^{17,18}$ There are $\sim 29$ million CpGs in the human genome, and $60-80 \%$ of them are methylated. ${ }^{19}$

\footnotetext{
${ }^{1}$ Personalized Genomic Medicine Research Center, Korea Research Institute of Bioscience and Biotechnology (KRIBB), Daejeon, Korea; ${ }^{2}$ Department of Functional Genomics, University of Science and Technology, Daejeon, Korea and ${ }^{3}$ Department of Neurological Surgery, University of California, San Francisco, CA, USA Correspondence: Professor J Costello, Department of Neurological Surgery, University of California, San Francisco, CA 94158, USA.

E-mail: joseph.costello@ucsf.edu
}

Received 9 December 2016; accepted 14 December 2016 
Approximately 7\% of CpGs are located in CpG islands (CGIs), which are regions of high CG density. ${ }^{20}$ Approximately $70 \%$ of annotated gene promoters are associated with a CGI, and CGIs are largely resistant to DNA methylation. ${ }^{21}$ The enzymes responsible for DNA methylation are DNA methyltransferases (DNMTs) including DNMT1, DNMT3A, DNMT3B and DNMT3C. ${ }^{22,23}$

In this section, we briefly describe the molecular mechanisms of maintenance and erasure of DNA methylation, as well as de novo methylation. We also introduce recent DNA methylation analysis technologies that can be used in clinical applications.

\section{MAINTENANCE AND ERASURE OF DNA METHYLATION}

DNA methylation patterns are transmitted with high fidelity during DNA replication. ${ }^{13}$ DNMT1 maintains global DNA methylation and shows a strong preference for hemimethylated DNA. ${ }^{24}$ DNMT1 is recruited to the DNA replication fork through direct interactions with PCNA (proliferating cell nuclear antigen) and UHRF1 (ubiquitin-like, containing PHD and RING finger domains 1, also known as Np95 and ICBP90). ${ }^{25,26}$ UHRF1 recognizes hemimethylation sites via an SRA domain and recruits DNMT1 to these sites. ${ }^{27}$ Chromatinassociated enzymes also regulate DNMT1 through posttranslational modifications. ${ }^{15}$ LSD1 (lysine-specific demethylase 1, also known as KDM1) is essential for maintaining global DNA methylation; it regulates the methylation status of DNMT1 and modulates its stability. ${ }^{28}$ Histone $\mathrm{H} 3$ lysine 9 methylation (H3K9me) is necessary for DNA methylation maintenance; it binds to UHRF1 and regulates DNMT1 stability during S phase. ${ }^{29}$ These interactions of DNMT1 with other heterochromatin-associated proteins ensure that DNMT1 activity is stabilized only during DNA replication, which provides fidelity to global DNA methylation. ${ }^{15}$

DNA methylation can be removed through passive and active mechanisms. Passive DNA demethylation occurs in the absence of functional DNA methylation maintenance machinery during successive rounds of replication. By contrast, active DNA demethylation occurs through an enzymatic process that removes or modifies the methyl group from $5 \mathrm{mC} .{ }^{30}$ Ten-eleven translocation (TET) family enzymes, such as TET1, TET2 and TET3, are involved in active demethylation. $^{31}$ TET proteins oxidize $5 \mathrm{mC}$ to 5-hydroxymethylcytosine $(5 \mathrm{hmC})$ and further oxidize $5 \mathrm{hmC}$ to generate 5 -formylcytosine and 5-carboxylcytosine. ${ }^{32}$ DNA demethylation can be completed by either replication-dependent dilution of $5 \mathrm{mC}$ oxidation derivatives or thymine-DNA glycosylase-mediated base excision repair. ${ }^{33,34}$

\section{DE NOVO DNA METHYLATION}

Many CGI promoters are protected from DNA methylation by transcription factor binding, nucleosome exclusion and H3K4 methyltransferases, such as SETD1A (SET domain containing 1A) or MLL proteins. ${ }^{15}$ Although these promoters remain unmethylated, some repressed promoters acquire DNA methylation during development. ${ }^{15}$ De novo DNA methylation is carried out by DNMT3A and DNMT3B complexed with DNMT3L, a closely related homolog that lacks a catalytic domain. ${ }^{35,36}$ DNMT3L interacts with unmethylated H3K4 and recruits the DNMTs. ${ }^{35}$

DNMT3A and DNMT3B are recruited to target promoters in complex with other epigenetic repressors, including histone deacetylases and $\mathrm{H} 3 \mathrm{~K} 9$ methyltransferases. ${ }^{15,37}$ Frequently, proper targeting to stable silencing regions occurs by the binding of repressive transcription factors. ${ }^{15}$ Repressive transcription factors induce chromatin remodeling by recruitment of LSH (lymphoid-specific helicase; also known as HELLS), linker histone $\mathrm{H} 1$ and heterochromatin protein 1. $\mathrm{H} 3 \mathrm{~K} 9$ methyltransferase, G9A is also recruited in this complex with DNMT3A or DNMT3B. ${ }^{37-40}$ The crosstalk between DNA methylation and histone modification suggests that histone modifications, such as $\mathrm{H} 3 \mathrm{~K} 9 \mathrm{me}$, initiate heterochromatin formation and subsequent DNA methylation ensures stable silencing of the promoter. ${ }^{15}$

\section{DNA METHYLATION ANALYSIS TECHNOLOGIES}

The three main principles of DNA methylation analysis are as follows: (1) digestion of genomic DNA with methylationsensitive restriction enzymes; (2) affinity-based enrichment of methylated DNA fragments; and (3) sodium bisulfite conversion. ${ }^{41}$ Although there are many DNA methylation analysis methods, bisulfite sequencing (BS) is widely accepted as a gold standard for detection of DNA methylation. ${ }^{42,43}$ BS is a sodium bisulfite conversion method that provides quantitative DNA methylation level with single-base resolution. Sodium bisulfite treatment of genomic DNA converts unmethylated cytosine to uracil and then uracil become thymidine in subsequent PCR amplification and sequencing. ${ }^{44} 5 \mathrm{mC}$ is resistant to this conversion and remains as cytosine, so it can be distinguished from unmethylated cytosine. ${ }^{44}$ Initially, BS was used to assay individual loci with locus-specific PCR followed by Sanger sequencing. ${ }^{44}$ Recently, reduced representation BS has extended the genomic coverage of BS by using high-throughput sequencing technology. Reduced representation BS combines restriction digestion with BS for analysis of high CpG density regions such as CGIs. ${ }^{45}$ Finally, wholegenome BS provides single-base resolution and quantitative rates of methylation for all cytosines in the genome. ${ }^{46,47}$ Whole-genome BS has been applied to various tissues and cell lines to provide a complete map of the $\sim 29$ million CpG sites in the human genome. ${ }^{19}$

The Infinium methylation $450 \mathrm{k}$ microarray is a costeffective, high-throughput method for detecting DNA methylation in many human samples. ${ }^{16}$ This assay involves bisulfite treatment of genomic DNA and subsequent hybridization to over $450000 \mathrm{CpG}$ sites throughout the genome. The coverage of this platform targets gene regions including promoters, $5^{\prime}$-untranslated regionss, the first exons, gene bodies and $3^{\prime}$-untranslated regionss. ${ }^{48}$ Notably, The Cancer Genome Atlas consortium used this platform to profile $>7500$ samples from over 200 different cancer types. ${ }^{49-52}$ The MethylationEPIC (EPIC) BeadChip, an advancement upon the 450k array, 


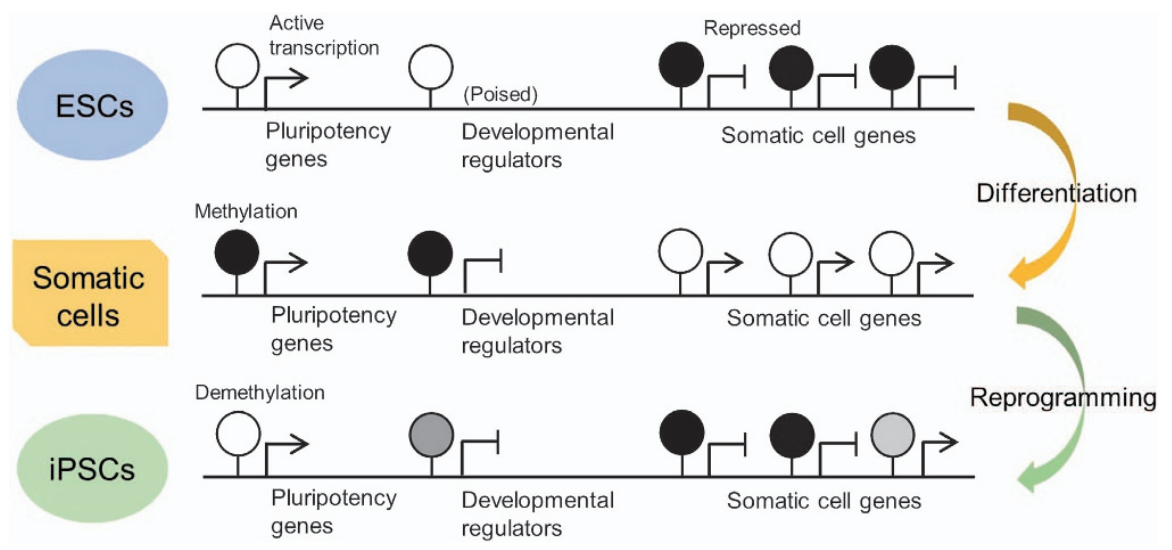

Figure $1 \mathrm{~A}$ model of epigenetic memory in iPSCs (modified from Ohi et al. ${ }^{66}$ ). Induced pluripotent stem cells (iPSCs) harbor residual DNA methylation signatures from their donor cells. During reprogramming, pluripotency genes are demethylated and reactivated. Incomplete demethylation occurs in developmental regulators that are silenced in the somatic cell. Somatic cell genes were differentially methylated and repressed in iPSCs. Black, white and gray circles represent methylated, unmethylated and partially methylated CpGs, respectively.

contains more than 850000 probes. The new platform covers $>90 \%$ of the sites on the $450 \mathrm{k}$ array, plus $>350000 \mathrm{CpGs}$ at regions identified as potential enhancers by FANTOM5 and the ENCODE project. ${ }^{53,54}$ The EPIC array is expected to be a valuable tool for understanding human development and disease, in particular enhancer DNA methylation. ${ }^{52}$

\section{DNA METHYLATION IN STEM CELLS}

Stem cells can be applied to cell therapy, drug development, disease modeling and the study of cellular differentiation. DNA methylation has critical roles in the maintenance of stem cell identity and lineage commitment during differentiation..$^{55}$ In this section, we describe DNA methylation as an epigenetic memory of stem cells such as ESCs, iPSCs, HSCs, MSCs and NSCs.

\section{EMBRYONIC STEM CELLS}

ESCs are pluripotent, self-renewing cells. It is known that ESCs can maintain their self-renewal ability even in the absence of all three DNMTs. ${ }^{56}$ However, the differentiation of ESCs is almost completely inhibited if DNMTs are not present. ${ }^{57}$ Global DNA hypomethylation blocks ESCs to silence pluripotency factors and to express differentiation-associated markers. ${ }^{57}$

ESCs exhibit significant levels of non-CpG methylation and express high levels of DNMT3A and DNMT3B. ${ }^{17,19}$ Non-CpG methylation, primarily at CpA sites, accounts for $\sim 25 \%$ of all methylated cytosines in human ESCs. ${ }^{19}$ Non-CG methylation is mediated by DNMT3A and DNMT3B, and depends on the presence of DNMT3L. DNMT3L may direct de novo DNMT activity during pluripotency, but it is silenced upon differentiation. ${ }^{58,59}$ The prevalence of non-CpG methylation in ESCs, as well as in iPSCs, suggests that it could be important for pluripotency, but it is currently unclear whether it is a cause or consequence of the pluripotent state. ${ }^{60}$

In contrast to somatic cells, which transmit considerable epigenetic information to daughter cells, ESCs preserve their epigenetic memory by balancing the addition and removal of
DNA methylation. ${ }^{4}$ Although ESCs show high DNA methylation turnover rates, their epigenomes are well organized and highly stable. ${ }^{4}$

\section{INDUCED PLURIPOTENT STEM CELLS}

iPSCs are originally generated through ectopic expression of four transcription factors: OCT4, SOX2, KLF4 and MYC. iPSCs can be used to uncover the epigenetic mechanisms of reprogramming. ${ }^{61}$ During reprogramming, a global reset of the mature somatic epigenome occurs, and the epigenomes of iPSCs are remarkably similar to those of ESCs. ${ }^{62,63}$ However, it has been discovered that iPSCs harbor residual DNA methylation signatures from their donor cells, and they exhibit a preference for differentiation into their original cell lineage (Figure 1). ${ }^{9,64,65}$ Moreover, a subset of human iPSCs retain their epigenetic memory even after extended passaging. ${ }^{10,66}$

Epigenetic memory has also been reported in direct reprogramming. Direct reprogramming is the conversion of fully differentiated cells to other cell types, bypassing an intermediate pluripotent stage. Direct reprogramming of fibroblasts into neural stem cells by defined factors shows that there is some epigenetic memory in fibroblasts, although the reprogrammed neural stem cells were able to suppress the donor cell-specific transcription network. ${ }^{67}$ All these studies of reprogramming technologies provide insight into epigenetic memory and show how it can potentially be used for disease modeling and therapeutic applications. ${ }^{68}$

\section{HEMATOPOIETIC STEM CELLS}

HSCs are a rare cell population that is responsible for generating erythroid, myeloid and lymphoid lineages ${ }^{69}$ DNA methylation is critical for the regulation of HSC self-renewal during hematopoiesis; it facilitates commitment to a lymphoid or myeloid fate, and it establishes the differentiated cell identity. ${ }^{69,70}$ DNMT1 is essential for protecting HSCs from the premature activation of predominant differentiation programs. ${ }^{69,71}$ Dnmt1-knockout mice suffer from self-renewal 
defects and marked misregulation of the myeloid and lymphoid compartments. ${ }^{70,71}$ On the other hand, DNMT3A and DNMT3B are required to repress the HSC self-renewal gene network during HSC differentiation. ${ }^{72}$ Combined loss of Dnmt3a and Dnmt3b shows enhanced HSC self-renewal and severe inhibition of differentiation. ${ }^{72}$

DNA methylation levels increase upon lymphoid commitment, but decrease with myeloid commitment. ${ }^{73}$ Although DNA hypomethylation is a general feature of myeloid cells, DNA methylation is dynamically regulated throughout the stages of differentiation. ${ }^{69}$ During neutrophil development, DNA methylation appears to change during specific differentiation stages, and its states overlap with changes in the activation of key hematopoietic transcription factors. ${ }^{74}$ During the differentiation of monocytes into macrophages and dendritic cells, the time course of demethylation occurs at individual CpG sites. ${ }^{75,76}$ However, de novo DNA methylation has rarely been detected during these differentiation processes. $^{75}$

\section{MESENCHYMAL STEM CELLS}

MSCs are multipotent adult stem cells that have self-renewal capacity, support hematopoiesis and can differentiate into osteocytes, chondrocytes and adipocytes. ${ }^{77}$ Human MSCs from various tissues, including bone marrow, umbilical cord, adipose tissue, dental pulp, skin and many others, have been used clinically as potential regenerative cell therapies. ${ }^{78}$ However, the high proliferation rate of MSCs in an artificial cell culture environment could favor genetic and epigenetic alterations. ${ }^{79,80}$ DNA methylation patterns of human MSCs are maintained throughout long-term culture and aging, but senescenceassociated DNA methylation differences are observed in regions with H3K9me3, H3K27me3 and targets of EZH $2 .{ }^{8}$ Therefore, DNA methylation can be a good molecular marker for the quality control of MSCs. ${ }^{80}$ The DNA methylation profiles of MSCs can reflect their cell type of origin and can be useful for the classification of MSCs. ${ }^{7,81}$

\section{NEURAL STEM CELLS}

NSCs are a subtype of progenitor cells in the nervous system that have the capacity to self-renew and to differentiate into distinct cell types such as neurons, astrocytes and oligodendrocytes. ${ }^{82}$ NSCs at early gestation can only self-renew, and they then differentiate exclusively into neurons during midgestation. At late gestation, NSCs begin to differentiate into astrocytes and oligodendrocytes. ${ }^{83}$ DNA methylation plays an important role in defining the timing of the NSC fate specification switch from neurogenesis to astrocytogenesis. ${ }^{84-86}$ Many astrocytic genes, such as GFAP (glial fibrillary acidic protein), are methylated in early and mid-gestational NSCs, then demethylated in late-stage NSCs. ${ }^{87,88}$ Thus, epigenetic mechanisms have a critical role in fine-tuning and coordinating gene expression during neurogenesis. ${ }^{86}$

$5 \mathrm{hmC}$ is present at much lower levels than $5 \mathrm{mC}$, but it is particularly abundant in brain tissue. ${ }^{89}$ DNA hydroxymethylation may play important roles in mediating dynamic gene expression changes during brain development. ${ }^{85,90}$ Intriguingly, Tet1 mutant mice also show adult neurogenesis deficits and impairment in learning and memory. ${ }^{91}$ It remains to be determined how $5 \mathrm{hmC}$ and DNA demethylation regulate neurogenesis. ${ }^{86}$

\section{DNA METHYLATION IN CANCER CELLS}

Aberrant DNA methylation is common across many types of cancer. Global hypomethylation of the cancer genome, promoter hypermethylation of tumor suppressor genes and potentially direct mutagenesis of $5 \mathrm{mC}$-containing sequences through deamination of methylated cytosine can contribute to cancer. ${ }^{16}$ These alterations generally co-exist in tumors, suggesting that epigenetic mechanisms are central to the evolution of human cancer. ${ }^{16}$ In this section, we describe epigenetic reprogramming during tumor initiation and describe the roles of DNA methylation in tumor evolution. We also describe DNA methylation as an epigenetic memory of cell or tissue origin of cancers and its utility as a molecular marker for classifying cancers of unknown primary (CUP).

\section{EPIGENETIC REPROGRAMMING DURING TUMOR INITIATION}

The malignant transformation of a normal cell into a cancerous cell has similarities to the reprogramming of a somatic cell to a pluripotent cell. ${ }^{92}$ Transformation resets the transcriptional network and chromatin structure and produces cells with unlimited self-renewal potential. ${ }^{92}$ Several reprogramming transcription factors, such as Sox2 and c-Myc, are wellknown oncogenes, whereas many genes that act as barriers to reprogramming, including p53 and Ink4A/Arf, function as tumor suppressors. ${ }^{93}$ DNA methylation is a potent barrier to cellular reprogramming, and the methylation changes markedly during malignant transformation, as it does in cellular reprogramming. ${ }^{94}$

Stem cell-like chromatin patterns frequently lead to DNA hypermethylation during cancer progression..$^{95}$ Hypermethylated genes in cancer are heavily biased to PRC2 (polycomb repressive complex 2)-regulated, $\mathrm{H} 3 \mathrm{~K} 27 \mathrm{me} 3$-marked genes, in ESCs and adult stem cells. ${ }^{95-97}$ Regions of focal DNA hypermethylation in cancer are located primarily at CGIs and are concentrated within long-range hypomethylated regions. ${ }^{98}$ In the nucleus, these hypomethylated regions correspond broadly to nuclear lamina-associated domains, which are generally associated with repressive chromatin and polycomb group protein-marked genes in ES cells. ${ }^{16,98,99}$

The widespread DNA methylation changes in cancer may be caused by mutations in components of the citric acid cycle and the epigenetic machinery. ${ }^{16}$ For example, mutations in IDH1 (isocitrate dehydrogenase 1) and $\mathrm{IDH} 2$ alter the DNA and histone demethylation pathways by causing the accumulation of D-2-hydroxyglutarate, which competes with the $\alpha$-ketoglutarate needed by the TET and histone lysine demethylase (KDM) enzymes. ${ }^{100,101}$ IDH1 and TET2 mutations are mutually exclusive in acute myeloid leukemia. ${ }^{102,103}$ Thus, 
interactions between epigenetic and genetic events drive progressive cellular abnormalities throughout the entire course of cancer development. ${ }^{16}$

\section{EPIGENETIC HETEROGENEITY AND TUMOR EVOLUTION}

According to the clonal evolution theory of tumor cell populations, cancers evolve by an iterative process of clonal expansion, genetic diversification and clonal selection within adaptive microenvironments. ${ }^{104,105}$ Genetic diversity is essential for tumor evolution. In addition, it is now thought that not only the genome but also the epigenome can contribute to tumor evolution and that the genome and epigenome are intertwined. ${ }^{106}$ For example, promoter DNA hypermethylation of DNA repair genes is known to cause genetic changes, and mutations of epigenetic modifiers can cause epigenetic disruptions. ${ }^{106}$ Although epigenetic modifications are enzymatically reversible, some epigenetic marks are retained through cancer progression and represent the history of the cancer cells (Figure 2). ${ }^{106-108}$ Epigenetic marks can also reflect the responsive potential of cancer cells to therapeutic treatment. ${ }^{106-108}$

Profiling intratumoral heterogeneity is a powerful way to reconstruct tumor evolution, from tumor initiation through the subsequent stepwise development of cancer. ${ }^{107,109}$ Recently, genome-wide profiling of intratumoral heterogeneity has been extended from genome to epigenome. Interestingly, intratumoral heterogeneity analyses in prostate cancers and gliomas have shown that the inferred histories from DNA methylation are remarkably similar to those obtained by looking at copynumber changes or somatic mutation. ${ }^{108,110,111}$ These studies suggest that genetic mechanisms and epigenetic mechanisms have widespread co-dependency during tumor evolution. ${ }^{107}$

Epigenetic heterogeneity in cancer has clinical importance for cancer diagnosis and treatment. ${ }^{109} \mathrm{~A}$ rare population of

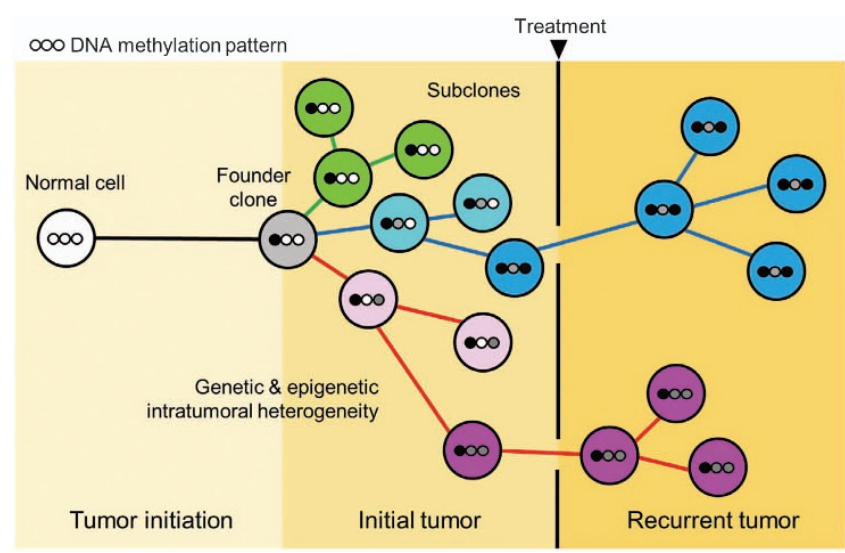

Figure $2 \mathrm{~A}$ model of epigenetic memory in cancer cells. Cancers evolve by an iterative process of clonal expansion, genetic and epigenetic diversification and clonal selection within adaptive microenvironments. DNA methylation can be retained as an epigenetic memory of tumor evolution. Vertical line represents cancer treatments such as chemotherapy and radiation therapy. Small circles filled with black, white and gray represent DNA methylation pattern. cancer cells with unique epigenetic states can drive drug resistance. ${ }^{112}$ In addition, the degree of epigenetic heterogeneity has been associated with patient response to drug treatment. ${ }^{107}$ Epigenetic heterogeneity at the single-cell level may play a role in determining the responses of patients to therapies, and concurrent treatment with epigenetic drugs against chromatin regulators can improve anti-cancer drug responses. ${ }^{113-115}$

\section{DNA METHYLATION PROFILING OF CUP}

CUP are a molecularly heterogeneous group of cancers for which the primary site remains obscure after metastasis. ${ }^{116,117}$ CUP accounts for $~ 3-9 \%$ of all cancer diagnoses, and it is the fourth most common cause of cancer-related deaths worldwide. ${ }^{117,118}$ Overall median survival of CUP patients is 9 months, and only $25 \%$ survive for 1 year or more. ${ }^{119,120}$ Identification of the primary tumor site and treatment with origin-selective therapy can improve the survival of CUP patients. ${ }^{117}$ Sophisticated imaging, immunohistochemical testing and molecular-profiling tools have been tested for the identification of primary sites in CUP cases. ${ }^{117}$

DNA methylation patterns are tumor-type specific, and methylation analysis has already been clinically successful for the pharmacogenetic management of gliomas. ${ }^{121-125} \mathrm{~A}$ recent attempt to diagnose primary sites for CUP by using DNA methylation signatures (EPICUP) is a promising advance for CUP patients. ${ }^{126}$ EPICUP shows $99.6 \%$ specificity and $97.7 \%$ sensitivity in the validation set of 7691 tumors. Furthermore, it predicted the tissue of origin in $188(87 \%)$ of 216 CUP patients. ${ }^{126}$ This achievement suggests that DNA methylation as an epigenetic memory of cancer cell origin can be a useful biomarker to unmask the original primary tumor site of a CUP, and it is clinically applicable for diagnosis and treatment of CUP patients.

\section{FUTURE PERSPECTIVES}

Intratumoral heterogeneity plays a critical role in cancer drug resistance. Single-cell analysis technologies for the genome, epigenome, transcriptome and proteome will make it possible to resolve such heterogeneity as these technologies become more available. ${ }^{127-129}$ Single-cell analysis of DNA methylation is technically difficult because bisulfite conversion is a relatively harsh process that causes DNA to be randomly fragmented. ${ }^{130}$ Although single-cell genome-wide BS technologies have been developed, more clinically available DNA methylation analysis tools are needed for rare cell populations such as stem cells, immune cells, circulating tumor cells and cell-free DNA. ${ }^{130-132}$ Though DNA methylation is critical in mammalian development and disease progression, the direct function of DNA methylation at specific sites remains unclear. Recently developed technologies for targeted DNA methylation editing, such as dCas9-Dnmt3a/Tet1, will be useful to validate the function of site-specific DNA methylation in gene expression and cellfate determination. ${ }^{133-137}$ The identification of cell of origin is essential to stem cell biology and cancer research. As an epigenetic memory of cell origin, DNA methylation profiles 
will be useful in the development of regenerative medicine and tumor-type-specific and patient type-specific treatments.

\section{CONFLICT OF INTEREST}

The authors declare no conflict of interest.

\section{ACKNOWLEDGEMENTS}

This work was supported by the National Research Foundation of Korea (NRF) grants funded by the Korean government

(NRF-2012M3A9B4027954), a KRIBB research initiative grant, the loglio project supported by the Dabbiere Family and grants from the National Institutes of Health, R01CA169316 and P50CA097257.

1 Bernstein BE, Meissner A, Lander ES. The mammalian epigenome. Cell 2007; 128: 669-681.

2 Bird A. DNA methylation patterns and epigenetic memory. Genes Dev 2002; 16: 6-21.

3 Hemberger M, Dean W, Reik W. Epigenetic dynamics of stem cells and cell lineage commitment: digging Waddington's canal. Nat Rev Mol Cell Biol 2009; 10: 526-537.

4 Shipony Z, Mukamel Z, Cohen NM, Landan G, Chomsky E, Zeliger SR et al. Dynamic and static maintenance of epigenetic memory in pluripotent and somatic cells. Nature 2014; 513: 115-119.

5 Halley-Stott RP, Gurdon JB. Epigenetic memory in the context of nuclear reprogramming and cancer. Brief Funct Genomics 2013; 12: 164-173.

6 Jaenisch R, Bird A. Epigenetic regulation of gene expression: how the genome integrates intrinsic and environmental signals. Nat Genet 2003; 33(Suppl): 245-254.

7 Reinisch A, Etchart N, Thomas D, Hofmann NA, Fruehwirth M, Sinha S et al. Epigenetic and in vivo comparison of diverse MSC sources reveals an endochondral signature for human hematopoietic niche formation. Blood 2015; 125: 249-260.

8 Schellenberg A, Lin Q, Schuler H, Koch CM, Joussen S, Denecke B et al. Replicative senescence of mesenchymal stem cells causes DNAmethylation changes which correlate with repressive histone marks. Aging 2011; 3: 873-888.

9 Kim K, Doi A, Wen B, Ng K, Zhao R, Cahan P et al. Epigenetic memory in induced pluripotent stem cells. Nature 2010; 467: 285-290.

10 Lister R, Pelizzola M, Kida YS, Hawkins RD, Nery JR, Hon G et al. Hotspots of aberrant epigenomic reprogramming in human induced pluripotent stem cells. Nature 2011; 471: 68-73.

11 Waddington $\mathrm{CH}$. The epigenotype. Endeavour 1942; 1 : 3.

12 Riggs AD, Martienssen RA, Russo VEA. Epigenetic Mechanisms of Gene Regulation. Cold Spring Harbor Laboratory Press: Cold Spring Harbor, NY, USA, 1996, pp 4.

13 Probst AV, Dunleavy E, Almouzni G. Epigenetic inheritance during the cell cycle. Nat Rev Mol Cell Biol 2009; 10: 192-206.

14 Fisher AG, Brockdorff N. Epigenetic memory and parliamentary privilege combine to evoke discussions on inheritance. Development 2012; 139 : 3891-3896.

15 Smith ZD, Meissner A. DNA methylation: roles in mammalian development. Nat Rev Genet 2013; 14: 204-220.

16 Baylin SB, Jones PA. Epigenetic determinants of cancer. Cold Spring Harb Perspect Biol 2016; 8: a019505.

17 Ramsahoye BH, Biniszkiewicz D, Lyko F, Clark V, Bird AP, Jaenisch R. Non-CpG methylation is prevalent in embryonic stem cells and may be mediated by DNA methyltransferase 3a. Proc Natl Acad Sci USA 2000; 97: 5237-5242.

18 Ziller MJ, Muller F, Liao J, Zhang Y, Gu H, Bock C et al. Genomic distribution and inter-sample variation of non-CpG methylation across human cell types. PLoS Genet 2011; 7: e1002389.

19 Lister R, Pelizzola M, Dowen RH, Hawkins RD, Hon G, Tonti-Filippini J et al. Human DNA methylomes at base resolution show widespread epigenomic differences. Nature 2009; 462: 315-322.

20 Deaton AM, Bird A. CpG islands and the regulation of transcription. Genes Dev 2011; 25: 1010-1022.
21 Saxonov S, Berg P, Brutlag DL. A genome-wide analysis of $\mathrm{CpG}$ dinucleotides in the human genome distinguishes two distinct classes of promoters. Proc Natl Acad Sci USA 2006; 103: 1412-1417.

22 Okano M, Bell DW, Haber DA, Li E. DNA methyltransferases Dnmt3a and Dnmt3b are essential for de novo methylation and mammalian development. Cell 1999; 99: 247-257.

23 Barau J, Teissandier A, Zamudio N, Roy S, Nalesso V, Herault Y et al. The DNA methyltransferase DNMT3C protects male germ cells from transposon activity. Science 2016; 354: 909-912.

24 Hermann A, Goyal R, Jeltsch A. The Dnmt1 DNA-(cytosine-C5)-methyltransferase methylates DNA processively with high preference for hemimethylated target sites. J Biol Chem 2004; 279: 48350-48359.

25 Chuang LS, Ian HI, Koh TW, Ng HH, Xu G, Li BF. Human DNA-(cytosine-5) methyltransferase-PCNA complex as a target for p21WAF1. Science 1997; 277: 1996-2000.

26 Bostick M, Kim JK, Esteve PO, Clark A, Pradhan S, Jacobsen SE. UHRF1 plays a role in maintaining DNA methylation in mammalian cells. Science 2007; 317: 1760-1764.

27 Arita K, Ariyoshi M, Tochio H, Nakamura Y, Shirakawa M. Recognition of hemi-methylated DNA by the SRA protein UHRF1 by a base-flipping mechanism. Nature 2008; 455: 818-821.

28 Wang J, Hevi S, Kurash JK, Lei H, Gay F, Bajko J et al. The lysine demethylase LSD1 (KDM1) is required for maintenance of global DNA methylation. Nat Genet 2009; 41: 125-129.

29 Rothbart SB, Krajewski K, Nady N, Tempel W, Xue S, Badeaux Al et al. Association of UHRF1 with methylated H3K9 directs the maintenance of DNA methylation. Nat Struct Mol Biol 2012; 19: 1155-1160.

30 Kohli RM, Zhang Y. TET enzymes, TDG and the dynamics of DNA demethylation. Nature 2013; 502: 472-479.

31 Ito S, D'Alessio AC, Taranova OV, Hong K, Sowers LC, Zhang Y. Role of Tet proteins in $5 \mathrm{mC}$ to $5 \mathrm{hmC}$ conversion, ES-cell self-renewal and inner cell mass specification. Nature 2010; 466: 1129-1133.

32 Ito S, Shen L, Dai Q, Wu SC, Collins LB, Swenberg JA et al. Tet proteins can convert 5-methylcytosine to 5-formylcytosine and 5-carboxylcytosine. Science 2011; 333: 1300-1303.

33 He YF, Li BZ, Li Z, Liu P, Wang Y, Tang Q et al. Tet-mediated formation of 5 -carboxylcytosine and its excision by TDG in mammalian DNA. Science 2011; 333: 1303-1307.

34 Maiti A, Drohat AC. Thymine DNA glycosylase can rapidly excise 5-formylcytosine and 5-carboxylcytosine: potential implications for active demethylation of CpG sites. J Biol Chem 2011; 286: 35334-35338.

35 Ooi SK, Qiu C, Bernstein E, Li K, Jia D, Yang Z et al. DNMT3L connects unmethylated lysine 4 of histone $\mathrm{H} 3$ to de novo methylation of DNA. Nature 2007; 448: 714-717.

36 Jia D, Jurkowska RZ, Zhang X, Jeltsch A, Cheng X. Structure of Dnmt3a bound to Dnmt3L suggests a model for de novo DNA methylation. Nature 2007; 449: 248-251.

37 Epsztejn-Litman S, Feldman N, Abu-Remaileh M, Shufaro Y, Gerson A, Ueda J et al. De novo DNA methylation promoted by G9a prevents reprogramming of embryonically silenced genes. Nat Struct Mol Biol 2008; 15: 1176-1183.

38 Zhu H, Geiman TM, Xi S, Jiang Q, Schmidtmann A, Chen T et al. Lsh is involved in de novo methylation of DNA. EMBO J 2006; 25: 335-345.

39 Ayyanathan K, Lechner MS, Bell P, Maul GG, Schultz DC, Yamada Y et al. Regulated recruitment of HP1 to a euchromatic gene induces mitotically heritable, epigenetic gene silencing: a mammalian cell culture model of gene variegation. Genes Dev 2003; 17: 1855-1869.

40 Myant K, Termanis A, Sundaram AY, Boe T, Li C, Merusi C et al. LSH and G9a/GLP complex are required for developmentally programmed DNA methylation. Genome Res 2011; 21: 83-94.

41 Laird PW. Principles and challenges of genomewide DNA methylation analysis. Nat Rev Genet 2010; 11: 191-203.

$42 \mathrm{Li} \mathrm{Y}$, Tollefsbol TO. DNA methylation detection: bisulfite genomic sequencing analysis. Methods Mol Biol 2011; 791: 11-21.

43 Rivera CM, Ren B. Mapping human epigenomes. Cell 2013; 155 : 39-55.

44 Frommer M, McDonald LE, Millar DS, Collis CM, Watt F, Grigg GW et al. A genomic sequencing protocol that yields a positive display of 5-methylcytosine residues in individual DNA strands. Proc Natl Acad Sci USA 1992; 89: 1827-1831.

45 Meissner A, Gnirke A, Bell GW, Ramsahoye B, Lander ES, Jaenisch R. Reduced representation bisulfite sequencing for comparative highresolution DNA methylation analysis. Nucleic Acids Res 2005; 33: 5868-5877. 
46 Cokus SJ, Feng S, Zhang X, Chen Z, Merriman B, Haudenschild CD et al. Shotgun bisulphite sequencing of the Arabidopsis genome reveals DNA methylation patterning. Nature 2008; 452: 215-219.

47 Lister R, O'Malley RC, Tonti-Filippini J, Gregory BD, Berry CC, Millar AH et al. Highly integrated single-base resolution maps of the epigenome in Arabidopsis. Cell 2008; 133: 523-536.

48 Dedeurwaerder S, Defrance M, Calonne E, Denis H, Sotiriou C, Fuks F. Evaluation of the Infinium methylation $450 \mathrm{~K}$ technology. Epigenomics 2011; 3: 771-784.

49 Cancer Genome Atlas Research Network. Comprehensive genomic characterization of squamous cell lung cancers. Nature 2012; 489: 519-525.

50 Cancer Genome Atlas Research Network. Comprehensive molecular characterization of clear cell renal cell carcinoma. Nature 2013; 499: 43-49.

51 Stirzaker C, Taberlay PC, Statham AL, Clark SJ. Mining cancer methylomes: prospects and challenges. Trends Genet 2014; 30: 75-84.

52 Pidsley R, Zotenko E, Peters TJ, Lawrence MG, Risbridger GP, Molloy P et al. Critical evaluation of the Illumina MethylationEPIC BeadChip microarray for whole-genome DNA methylation profiling. Genome Biol 2016; 17: 208.

53 Lizio M, Harshbarger J, Shimoji H, Severin J, Kasukawa T, Sahin S et al. Gateways to the FANTOM5 promoter level mammalian expression atlas. Genome Biol 2015; 16: 22.

54 Siggens L, Ekwall K. Epigenetics, chromatin and genome organization recent advances from the ENCODE project. J Intern Med 2014; 276: 201-214.

55 Kim M, Kang TW, Lee HC, Han YM, Kim H, Shin HD et al. Identification of DNA methylation markers for lineage commitment of in vitro hepatogenesis. Hum Mol Genet 2011; 20: 2722-2733.

56 Tsumura A, Hayakawa T, Kumaki Y, Takebayashi S, Sakaue M, Matsuoka C et al. Maintenance of self-renewal ability of mouse embryonic stem cells in the absence of DNA methyltransferases Dnmt1, Dnmt3a and Dnmt3b. Genes Cells 2006; 11: 805-814.

57 Jackson M, Krassowska A, Gilbert N, Chevassut T, Forrester L, Ansell J et al. Severe global DNA hypomethylation blocks differentiation and induces histone hyperacetylation in embryonic stem cells. Mol Cell Biol 2004; 24: 8862-8871.

58 Hu YG, Hirasawa R, Hu JL, Hata K, Li CL, Jin Y et al. Regulation of DNA methylation activity through Dnmt3L promoter methylation by Dnmt3 enzymes in embryonic development. Hum Mol Genet 2008; 17: 2654-2664.

59 Arand J, Spieler D, Karius T, Branco MR, Meilinger D, Meissner A et al. In vivo control of $\mathrm{CpG}$ and non-CpG DNA methylation by DNA methyltransferases. PLoS Genet 2012; 8: e1002750.

60 Patil V, Ward RL, Hesson LB. The evidence for functional non-CpG methylation in mammalian cells. Epigenetics 2014; 9: 823-828.

61 Takahashi K, Yamanaka S. Induction of pluripotent stem cells from mouse embryonic and adult fibroblast cultures by defined factors. Cell 2006; 126: 663-676.

62 Bock C, Kiskinis E, Verstappen G, Gu H, Boulting G, Smith ZD et al. Reference Maps of human ES and iPS cell variation enable highthroughput characterization of pluripotent cell lines. Cell 2011; 144 . 439-452.

63 Maherali N, Sridharan R, Xie W, Utikal J, Eminli S, Arnold K et al. Directly reprogrammed fibroblasts show global epigenetic remodeling and widespread tissue contribution. Cell Stem Cell 2007; 1: 55-70.

64 Polo JM, Liu S, Figueroa ME, Kulalert W, Eminli S, Tan KY et al. Cell type of origin influences the molecular and functional properties of mouse induced pluripotent stem cells. Nat Biotechnol 2010; 28: 848-855.

65 Bar-Nur O, Russ HA, Efrat S, Benvenisty N. Epigenetic memory and preferential lineage-specific differentiation in induced pluripotent stem cells derived from human pancreatic islet beta cells. Cell Stem Cell 2011; 9: 17-23.

66 Ohi Y, Qin H, Hong C, Blouin L, Polo JM, Guo T et al. Incomplete DNA methylation underlies a transcriptional memory of somatic cells in human iPS cells. Nat Cell Biol 2011; 13: 541-549.

67 Han DW, Tapia N, Hermann A, Hemmer K, Hoing S, Arauzo-Bravo MJ et al. Direct reprogramming of fibroblasts into neural stem cells by defined factors. Cell Stem Cell 2012; 10: 465-472.

68 Firas J, Liu X, Polo JM. Epigenetic memory in somatic cell nuclear transfer and induced pluripotency: evidence and implications. Differentiation 2014: 88: 29-32.
69 Alvarez-Errico D, Vento-Tormo R, Sieweke M, Ballestar E. Epigenetic control of myeloid cell differentiation, identity and function. Nat Rev Immunol 2015; 15: 7-17.

70 Trowbridge JJ, Snow JW, Kim J, Orkin SH. DNA methyltransferase 1 is essential for and uniquely regulates hematopoietic stem and progenitor cells. Cell Stem Cell 2009; 5: 442-449.

71 Broske AM, Vockentanz L, Kharazi S, Huska MR, Mancini E, Scheller M et al. DNA methylation protects hematopoietic stem cell multipotency from myeloerythroid restriction. Nat Genet 2009; 41: 1207-1215.

72 Challen GA, Sun D, Mayle A, Jeong M, Luo M, Rodriguez B et al. Dnmt3a and Dnmt3b have overlapping and distinct functions in hematopoietic stem cells. Cell Stem Cell 2014; 15: 350-364.

73 Ji H, Ehrlich LI, Seita J, Murakami P, Doi A, Lindau P et al. Comprehensive methylome map of lineage commitment from haematopoietic progenitors. Nature 2010; 467: 338-342.

74 Ronnerblad M, Andersson R, Olofsson T, Douagi I, Karimi M, Lehmann S et al. Analysis of the DNA methylome and transcriptome in granulopoiesis reveals timed changes and dynamic enhancer methylation. Blood 2014; 123: e79-e89.

75 Klug M, Heinz S, Gebhard C, Schwarzfischer L, Krause SW, Andreesen R et al. Active DNA demethylation in human postmitotic cells correlates with activating histone modifications, but not transcription levels. Genome Biol 2010; 11: R63.

76 Klug M, Schmidhofer S, Gebhard C, Andreesen R, Rehli M. 5-Hydroxymethylcytosine is an essential intermediate of active DNA demethylation processes in primary human monocytes. Genome Biol 2013; 14: R46.

77 Friedenstein AJ, Petrakova KV, Kurolesova Al, Frolova GP. Heterotopic of bone marrow. Analysis of precursor cells for osteogenic and hematopoietic tissues. Transplantation 1968; 6: 230-247.

78 Mendicino M, Bailey AM, Wonnacott K, Puri RK, Bauer SR. MSC-based product characterization for clinical trials: an FDA perspective. Cell Stem Cell 2014; 14: 141-145.

79 Bentivegna A, Roversi G, Riva G, Paoletta L, Redaelli S, Miloso M et al. The Effect of Culture on Human Bone Marrow Mesenchymal Stem Cells: Focus on DNA Methylation Profiles. Stem Cells Int 2016; 2016 : 5656701.

80 Wagner W, Frobel J, Goetzke R. Epigenetic quality check-how good are your mesenchymal stromal cells? Epigenomics 2016; 8: 889-894.

81 de Almeida DC, Ferreira MR, Franzen J, Weidner Cl, Frobel J, Zenke M et al. Epigenetic classification of human mesenchymal stromal cells. Stem Cell Rep 2016; 6: 168-175.

82 Steiner B, Wolf $\mathrm{S}$, Kempermann G. Adult neurogenesis and neurodegenerative disease. Regen Med 2006; 1: 15-28.

83 Temple S. The development of neural stem cells. Nature 2001; 414: 112-117.

84 Juliandi B, Abematsu M, Nakashima K. Epigenetic regulation in neural stem cell differentiation. Dev Growth Differ 2010; 52: 493-504.

85 Kim M, Park YK, Kang TW, Lee SH, Rhee YH, Park JL et al. Dynamic changes in DNA methylation and hydroxymethylation when hES cells undergo differentiation toward a neuronal lineage. Hum Mol Genet 2014; 23: 657-667.

86 Hsieh J, Zhao X. Genetics and epigenetics in adult neurogenesis. Cold Spring Harb Perspect Biol 2016; 8: a018911.

87 Takizawa T, Nakashima K, Namihira M, Ochiai W, Uemura A, Yanagisawa M et al. DNA methylation is a critical cell-intrinsic determinant of astrocyte differentiation in the fetal brain. Dev Cell 2001; 1: 749-758.

88 Hatada I, Namihira M, Morita S, Kimura M, Horii T, Nakashima K. Astrocyte-specific genes are generally demethylated in neural precursor cells prior to astrocytic differentiation. PloS ONE 2008; 3: e3189.

89 Shen L, Zhang Y. 5-Hydroxymethylcytosine: generation, fate, and genomic distribution. Curr Opin Cell Biol 2013; 25: 289-296.

90 Guo JU, Su Y, Zhong C, Ming GL, Song H. Hydroxylation of 5-methylcytosine by TET1 promotes active DNA demethylation in the adult brain. Cell 2011; 145: 423-434.

91 Zhang RR, Cui QY, Murai K, Lim YC, Smith ZD, Jin S et al. Tet1 regulates adult hippocampal neurogenesis and cognition. Cell Stem Cell 2013; 13: 237-245.

92 Suva ML, Riggi N, Bernstein BE. Epigenetic reprogramming in cancer. Science 2013; 339: 1567-1570.

93 Orkin SH, Hochedlinger K. Chromatin connections to pluripotency and cellular reprogramming. Cell 2011; 145: 835-850.

94 Mikkelsen TS, Hanna J, Zhang X, Ku M, Wernig M, Schorderet P et al. Dissecting direct reprogramming through integrative genomic analysis. Nature 2008; 454: 49-55. 
95 Ohm JE, McGarvey KM, Yu X, Cheng L, Schuebel KE, Cope L et al. A stem cell-like chromatin pattern may predispose tumor suppressor genes to DNA hypermethylation and heritable silencing. Nat Genet 2007; 39: 237-242.

96 Schlesinger Y, Straussman R, Keshet I, Farkash S, Hecht M, Zimmerman J et al. Polycomb-mediated methylation on Lys 27 of histone $\mathrm{H} 3$ pre-marks genes for de novo methylation in cancer. Nat Genet 2007; 39: 232-236.

97 Widschwendter M, Fiegl H, Egle D, Mueller-Holzner E, Spizzo G, Marth C et al. Epigenetic stem cell signature in cancer. Nat Genet 2007; 39: 157-158.

98 Berman BP, Weisenberger DJ, Aman JF, Hinoue T, Ramjan Z, Liu Y et al. Regions of focal DNA hypermethylation and long-range hypomethylation in colorectal cancer coincide with nuclear lamina-associated domains. Nat Genet 2011; 44: 40-46.

99 Peric-Hupkes D, Meuleman W, Pagie L, Bruggeman SW, Solovei I, Brugman $\mathrm{W}$ et al. Molecular maps of the reorganization of genomenuclear lamina interactions during differentiation. Mol Cell 2010; 38 603-613.

100 Lu C, Ward PS, Kapoor GS, Rohle D, Turcan S, Abdel-Wahab 0 et al. IDH mutation impairs histone demethylation and results in a block to cell differentiation. Nature 2012; 483: 474-478.

101 Lu C, Venneti S, Akalin A, Fang F, Ward PS, Dematteo RG et al. Induction of sarcomas by mutant IDH2. Genes Dev 2013; 27: 1986-1998.

102 Cairns RA, Mak TW. Oncogenic isocitrate dehydrogenase mutations: mechanisms, models, and clinical opportunities. Cancer Discov 2013; 3: 730-741.

103 Figueroa ME, Abdel-Wahab O, Lu C, Ward PS, Patel J, Shih A et al. Leukemic IDH1 and IDH2 mutations result in a hypermethylation phenotype, disrupt TET2 function, and impair hematopoietic differentiation. Cancer Cell 2010; 18: 553-567.

104 Nowell PC. The clonal evolution of tumor cell populations. Science 1976; 194: 23-28.

105 Greaves M, Maley CC. Clonal evolution in cancer. Nature 2012; 481: 306-313.

106 Alizadeh AA, Aranda V, Bardelli A, Blanpain C, Bock C, Borowski C et al. Toward understanding and exploiting tumor heterogeneity. Nat Med 2015; 21: 846-853.

107 Mazor T, Pankov A, Song JS, Costello JF. Intratumoral heterogeneity of the epigenome. Cancer Cell 2016; 29: 440-451.

108 Brocks D, Assenov Y, Minner S, Bogatyrova O, Simon R, Koop C et al. Intratumor DNA methylation heterogeneity reflects clonal evolution in aggressive prostate cancer. Cell Rep 2014; 8: 798-806.

109 Marusyk A, Almendro V, Polyak K. Intra-tumour heterogeneity: a looking glass for cancer? Nat Rev Cancer 2012; 12: 323-334.

110 Aryee MJ, Liu W, Engelmann JC, Nuhn P, Gurel M, Haffner MC et al. DNA methylation alterations exhibit intraindividual stability and interindividual heterogeneity in prostate cancer metastases. Sci Transl Med 2013; 5: $169 r a 110$.

111 Mazor T, Pankov A, Johnson BE, Hong C, Hamilton EG, Bell RJ et al. DNA Methylation and Somatic Mutations Converge on the Cell Cycle and Define Similar Evolutionary Histories in Brain Tumors. Cancer Cell 2015; 28 : 307-317.

112 Sharma SV, Lee DY, Li B, Quinlan MP, Takahashi F, Maheswaran S et al. A chromatin-mediated reversible drug-tolerant state in cancer cell subpopulations. Cell 2010; 141: 69-80.

113 Fang F, Munck J, Tang J, Taverna P, Wang Y, Miller DF et al. The novel, small-molecule DNA methylation inhibitor SGI-110 as an ovarian cancer chemosensitizer. Clin Cancer Res 2014; 20: 6504-6516.

114 Strauss J, Figg WD. Using epigenetic therapy to overcome chemotherapy resistance. Anticancer Res 2016; 36: 1-4.

115 Dawson MA, Kouzarides T. Cancer epigenetics: from mechanism to therapy. Cell 2012; 150: 12-27.

116 Briasoulis E, Tolis C, Bergh J, Pavlidis N, Force EGT. ESMO minimum clinical recommendations for diagnosis, treatment and follow-up of cancers of unknown primary site (CUP). Ann Oncol 2005; 16(Suppl 1): i75-i76.

117 Varadhachary GR, Raber MN. Cancer of unknown primary site. N Eng/ J Med 2014; 371: 757-765.

118 Pavlidis N, Pentheroudakis G. Cancer of unknown primary site. Lancet 2012; 379: 1428-1435
119 Greco FA, Pavlidis N. Treatment for patients with unknown primary carcinoma and unfavorable prognostic factors. Semin Oncol 2009; 36: 65-74.

120 Massard C, Loriot Y, Fizazi K. Carcinomas of an unknown primary origindiagnosis and treatment. Nat Rev Clin Oncol 2011; 8: 701-710.

121 Esteller M, Garcia-Foncillas J, Andion E, Goodman SN, Hidalgo OF, Vanaclocha $\mathrm{V}$ et al. Inactivation of the DNA-repair gene MGMT and the clinical response of gliomas to alkylating agents. N Engl J Med 2000; 343: 1350-1354.

122 Hegi ME, Diserens AC, Gorlia T, Hamou MF, de Tribolet N, Weller M et al. MGMT gene silencing and benefit from temozolomide in glioblastoma. $N$ Engl J Med 2005; 352: 997-1003.

123 Fernandez AF, Assenov Y, Martin-Subero JI, Balint B, Siebert R, Taniguchi $\mathrm{H}$ et al. A DNA methylation fingerprint of 1628 human samples. Genome Res 2012; 22: 407-419.

124 Costello JF, Fruhwald MC, Smiraglia DJ, Rush LJ, Robertson GP, Gao X et al. Aberrant CpG-island methylation has non-random and tumour-typespecific patterns. Nat Genet 2000; 24: 132-138.

125 Melki JR, Vincent PC, Clark SJ. Concurrent DNA hypermethylation of multiple genes in acute myeloid leukemia. Cancer Res 1999; 59: 3730-3740.

126 Moran S, Martinez-Cardus A, Sayols S, Musulen E, Balana C, Estival-Gonzalez A et al. Epigenetic profiling to classify cancer of unknown primary: a multicentre, retrospective analysis. Lancet Oncol 2016; 17: $1386-1395$.

127 Heath JR, Ribas A, Mischel PS. Single-cell analysis tools for drug discovery and development. Nat Rev Drug Discov 2016; 15: 204-216.

128 Schwartzman 0, Tanay A. Single-cell epigenomics: techniques and emerging applications. Nat Rev Drug Discov 2015; 16: 716-726.

129 Wei W, Shin YS, Xue M, Matsutani T, Masui K, Yang H et al. Single-cell phosphoproteomics resolves adaptive signaling dynamics and informs targeted combination therapy in glioblastoma. Cancer Cell 2016; 29: 563-573.

130 Farlik M, Sheffield NC, Nuzzo A, Datlinger P, Schonegger A, Klughammer J et al. Single-cell DNA methylome sequencing and bioinformatic inference of epigenomic cell-state dynamics. Cell Rep 2015; 10: $1386-1397$.

131 Guo H, Zhu P, Wu X, Li X, Wen L, Tang F. Single-cell methylome landscapes of mouse embryonic stem cells and early embryos analyzed using reduced representation bisulfite sequencing. Genome Res 2013; 23: 2126-2135.

132 Smallwood SA, Lee HJ, Angermueller C, Krueger F, Saadeh H, Peat J et al. Single-cell genome-wide bisulfite sequencing for assessing epigenetic heterogeneity. Nat Methods 2014; 11: 817-820.

133 Vojta A, Dobrinic P, Tadic V, Bockor L, Korac P, Julg B et al. Repurposing the CRISPR-Cas9 system for targeted DNA methylation. Nucleic Acids Res 2016; 44: 5615-5628.

134 Choudhury SR, Cui Y, Lubecka K, Stefanska B, Irudayaraj J. CRISPRdCas9 mediated TET1 targeting for selective DNA demethylation at BRCA1 promoter. Oncotarget 2016; 7: 46545-46556.

135 Xu X, Tao Y, Gao X, Zhang L, Li X, Zou W et al. A CRISPR-based approach for targeted DNA demethylation. Cell Discov 2016; 2: 16009.

136 Liu XS, Wu H, Ji X, Stelzer Y, Wu X, Czauderna S et al. Editing DNA methylation in the mammalian genome. Cell 2016; 167: 233-247e217.

137 Maeder ML, Angstman JF, Richardson ME, Linder SJ, Cascio VM, Tsai SQ et al. Targeted DNA demethylation and activation of endogenous genes using programmable TALE-TET1 fusion proteins. Nat Biotechnol 2013; 31: 1137-1142.

This work is licensed under a Creative Commons Attribution-NonCommercial-NoDerivs 4.0 International License. The images or other third party material in this article are included in the article's Creative Commons license, unless indicated otherwise in the credit line; if the material is not included under the Creative Commons license, users will need to obtain permission from the license holder to reproduce the material. To view a copy of this license, visit http://creativecommons.org/licenses/by-nc-nd/4.0/ 